\title{
FRESH KILLS
}





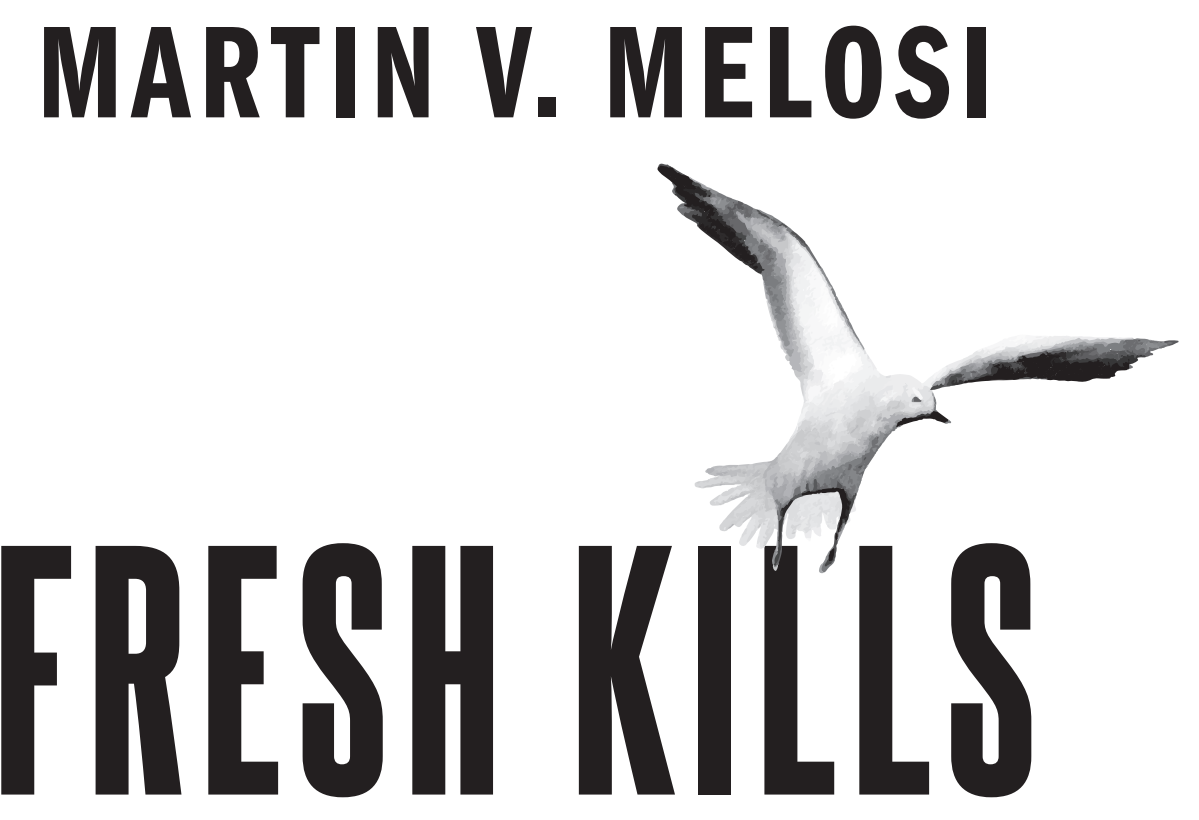

\section{A HISTORY OF CONSUMING AND DISCARDING IN NEW YORK CITY}

Columbia University Press

New York 


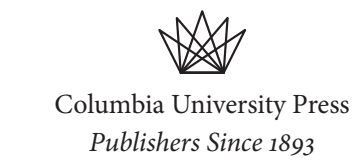

New York Chichester, West Sussex

cup.columbia.edu

Copyright (C) 2020 Columbia University Press

All rights reserved

Library of Congress Cataloging-in-Publication Data

Names: Melosi, Martin V., 1947- author.

Title: Fresh Kills : a history of consuming and discarding in New York City /

Martin V. Melosi.

Description: New York : Columbia University Press, 2020. | Includes bibliographical references and index.

Identifiers: LCCN 2019023877 (print) | LCCN 2019023878 (ebook) | ISBN

9780231189484 (cloth) | ISBN 9780231189491 (paperback) | ISBN 9780231548359

(ebook)

Subjects: LCSH: Sanitary landfill closures—New York (State)—New York. | Fresh Kills

Landfill (New York, N.Y.) | Freshkills Park (New York, N.Y.)

Classification: LCC TD788.4.N72 M45 2020 (print) | LCC TD788.4.N72 (ebook) |

DDC 628.4/45640974726-dc23

LC record available at https://lccn.loc.gov/2019023877

LC ebook record available at https://lccn.loc.gov/2019023878

Columbia University Press books are printed on permanent and durable acid-free paper.

Printed in the United States of America

Cover image: Digital composite. (c) Diane Cook and Fotosearch/Getty Images and Len Jenshel/Getty Images

Cover design: Lisa Hamm 
For Gianna and Angelina 
